\title{
EFICÁCIA DE HERBICIDAS NO MANEJO DE PLANTAS DANINHAS PARA O PLANTIO DIRETO DE SOJA
}

\author{
Fernando T. de Carvalho ${ }^{1}$ e Maurício A. Cavazzana ${ }^{2}$
}

\author{
'Engenheiro Agrônomo, Dr., Professor. FEIS/UNESP. Av. Brasil, 56. Caixa Postal 31. Ilha Solteira, SP 15385-000 ftadeu@bio.feis.unesp.br \\ ${ }^{2}$ Graduando de Agronomia. FEIS/UNESP.
}

\begin{abstract}
RESUMO
O experimento foi desenvolvido na safra 99/00, na Fazenda Sementes Maggi 2, em Rondonópolis-MT, enquadrada em região de Cerrado, em solo com textura argilosa. O objetivo foi avaliar a eficácia agronômica e os efeitos fitotóxicos de herbicidas pós-emergentes no manejo de plantas daninhas adultas para o plantio direto de soja. A variedade utilizada foi a Emgopa 313. A semeadura foi realizada em área contendo plantas daninhas adultas, no sistema "plantio direto sobre o mato". Os herbicidas selecionados para o teste experimental foram aplicados na operação de manejo, em pós-emergência das plantas daninhas e pré-semeadura da cultura. O delineamento experimental adotado foi o de blocos ao acaso, com sete tratamentos e quatro repetições. Os tratamentos foram os seguintes: glyphosate (960 e 1920 g/ha), chlorimuronethyl+glyphosate $(10+960$ e 20+960 g/ha), chlorimuron-ethyl+glyphosate+flumioxazin $(20+960+40 \mathrm{~g} / \mathrm{ha})$, glyphosate $+2,4-$ D $(960+868 \mathrm{~g} / \mathrm{ha})$ e testemunha no mato. Avaliou-se a eficiência dos herbicidas na dessecação das plantas daninhas e o efeito residual dos tratamentos. Não foram observados sintomas de fitotoxicidade dos tratamentos às plantas de soja. As principais espécies daninhas que ocorreram no experimento foram Commelina benghalensis, Cenchrus echinatus e Bidens pilosa. Todos os tratamentos foram eficientes na dessecação das plantas daninhas estudadas, exceto glyphosate isolado para $C$. benghalensis. O herbicida chlorimuron-ethyl (10 e $20 \mathrm{~g} / \mathrm{ha})$ aplicado juntamente com o glyphosate, no manejo, proporcionou ao tratamento um efeito residual significativo para Bidens pilosa, reduzindo a infestação da planta daninha durante o ciclo da cultura da soja.
\end{abstract}

Palavras-chave: Glycine $\max$, glyphosate, chlorimuron-ethyl, flumioxazin.

\section{ABSTRACT \\ Efficacy of desiccant herbicides in no-till soybean}

This research was done to evaluate the tolerance and efficacy of postemergence herbicides to control established weeds in no-till soybean. Experiment was conducted at Rondonópolis, Mato Grosso, from 1999 to 2000, in the Sementes Maggi 2 Farm, on a loamy texture soil, using Emgopa 313 variety. Planting was done in an area with adult weeds, in the system of "direct planting on the weeds". Herbicides were applied in postemergence of the weeds and the culture. Experimental design was a randomized complete block with seven treatments and four replications. The treatments were as follow: glyphosate (960 and $1920 \mathrm{~g} / \mathrm{ha})$, chlorimuron-ethyl+glyphosate (10+960 and 20+960 g/ha), chlorimuron-ethyl+glyphosate+flumioxazin $(20+960+40 \mathrm{~g} /$ ha), glyphosate+2,4-D $(960+868 \mathrm{~g} / \mathrm{ha})$ and untreated check plot. Efficacy of herbicides was evaluated in the base of controlling adult weeds and the residual effect of the treatments. No injury on soybean was caused by any treatment. Weeds found in the experimental area were: Commelina benghalensis, Cenchrus echinatus and Bidens pilosa. All treatments were efficient in the control of the studied weeds, except for glyphosate isolated, in C. benghalensis. Chlorimuron-ethyl (10 and $20 \mathrm{~g} / \mathrm{ha})$ applied 
together with glyphosate, provided a significant residual effect for Bidens pilosa, reducing the occurrence of the weed during the entire soybean cycle.

Key words: Glycine max, glyphosate, clhorimuron-ethyl, flumioxazin.

\section{INTRODUÇÃO}

Vários trabalhos publicados, baseados em médias mundiais, situam as plantas daninhas como as maiores responsáveis pela queda de produção da soja, em comparação com ataques de pragas e patógenos. As perdas mundiais de produção de soja, por ano, devido à ocorrência de plantas daninhas, são em média de 13\% (Associação Nacional de Defesa Vegetal - ANDEF, 1987). Entretanto, no clima tropical do Brasil, tem sido observado perdas bem maiores.

Blanco et al. (1973 e 1978) observaram prejuízos na produtividade da soja que variaram de 42 a $95 \%$, dependendo das espécies daninhas infestantes. Carvalho (1993) observou perdas médias de produtividade de $52,6 \%$ na testemunha infestada em relação à testemunha no limpo, para o cultivar Paraná. Spadotto et al. (1994) observaram perdas médias de produtividade de $42,4 \%$ na testemunha infestada por plantas daninhas de folhas largas, em relação à testemunha no limpo, para a cultivar IAC-8.

Uma das tecnologias utilizadas para a soja é o cultivo sem o revolvimento do solo. A prática, conhecida como plantio direto e utilizada em várias culturas, tem como principal vantagem a conservação do solo. No entanto, um dos principais problemas que tem se detectado no cultivo direto é a ocorrência de plantas daninhas e suas interações com o ambiente, prejudicando as plantas cultivadas.

Existem diferentes métodos para o controle das plantas daninhas. Na cultura da soja, devido às extensas áreas cultivadas, o controle químico é o que tem sido mais utilizado. No plantio direto o controle das invasoras, também, depende da utilização de herbicidas, uma vez que os cultivos e capinas são incompatíveis com a tecnologia utilizada no sistema.

No plantio direto é necessário a utilização de herbicidas de manejo, aplicados antes da semeadura da cultura, para a formação da palhada. Os herbicidas mais utilizados, nesta prática, são os dessecantes sem efeito residual, como o glyphosate e o paraquat. A utilização de herbicidas no manejo, que permitam um efeito residual no solo, poderia ser uma solução para reduzir a infestação de plantas daninhas em pós-emergência da cultura e, consequentemente, provocar uma economia nos custos desta operação.

O objetivo do trabalho foi avaliar a eficiência agronômica e os efeitos fitotóxicos de herbicidas pós-emergentes no manejo de plantas daninhas adultas para o plantio direto de soja.

\section{MATERIAL E MÉTODOS}

O experimento foi instalado e conduzido no período de dezembro de 1999 a fevereiro de 2000, na Fazenda Sementes Maggi 2, situada no município de Rondonópolis, MT, enquadrada em região de Cerrado. O solo da área experimental é classificado como Latossolo Vermelho-Escuro, textura argilosa, com $43,4 \%$ de argila, $49,9 \%$ de areia e $6,7 \%$ de silte. O teor de matéria orgânica era de 2,9\% e o pH (em água) de 5,8.

A variedade de soja utilizada foi a Emgopa 313, semeada mecanicamente em 02/12/99, no espaçamento de 0,45 m entre linhas. A semeadura foi realizada em área contendo plantas daninhas adultas, no sistema "plantio direto sobre o mato". A emergência da cultura foi beneficiada pelas chuvas que ocorreram após a semeadura (Anexo 1).

Os tratos culturais realizados na área experimental foram os normais, no que diz respeito às adubações e ao controle de pragas e doenças. A adubação foi realizada concomitantemente à semeadura, utilizando-se a fórmula comercial 0-20-20, à base de $450 \mathrm{~kg} / \mathrm{ha}$. Foram realizadas três aplicações de inseticida, entre o florescimento e enchimento de grãos da cultura, para o controle de lagartas e percevejos.

Os herbicidas selecionados para o teste experimental (Tabela 1) foram aplicados na operação de manejo em pósemergência das plantas daninhas e pré-semeadura da cultura. Não foi realizado o controle de plantas daninhas em pós-emergência da cultura com o intuito de não se mascarar o efeito residual dos herbicidas aplicados na dessecação.

O delineamento experimental adotado foi o de blocos ao acaso, com sete tratamentos e quatro repetições. Cada parcela constou de dez linhas da cultura com $5 \mathrm{~m}$ de comprimento e 4,5 m de largura, totalizando $22,5 \mathrm{~m}^{2}$, com $20 \mathrm{~m}^{2}$ de área aplicada. A área total do experimento foi de $630 \mathrm{~m}^{2}\left(22,5 \mathrm{~m}^{2} \times 28\right.$ parcelas).

As aplicações dos herbicidas foram realizadas com um pulverizador costal com pressão constante $\left(\mathrm{CO}_{2}\right)$ de $2,1 \mathrm{~kg}$ / $\mathrm{cm}^{2}$, provido de tanque com capacidade de dois litros (garrafas descartáveis), e com barra equipada com quatro bicos do tipo leque, (Teejet $110.02 \mathrm{XR}$ ), espaçados de $0,5 \mathrm{~m}$. O volume de calda aplicado foi de 200 litros por hectare. As condições no momento das aplicações estão descritas na Tabela 2.

A eficiência dos herbicidas na dessecação das plantas daninhas foi avaliada aos 15, 21 e 30 dias após a aplicação (DAA) dos tratamentos. Utilizou-se uma escala visual onde $0 \%=$ nenhum controle e $100 \%=$ controle total das plantas daninhas. Considerou-se como eficiente o controle igual ou superior a $80 \%$. Avaliou-se também a reinfestação das plantas 
Tabela 1. Tratamentos utilizados no experimento. Rondonópolis, MT, 1999-2000.

\begin{tabular}{|c|c|c|c|}
\hline \multirow{2}{*}{ Tratamento $^{1}$} & \multicolumn{2}{|c|}{ Dose dos herbicidas $^{7}$} & \multirow{2}{*}{$\begin{array}{l}\text { Época de } \\
\text { aplicação }\end{array}$} \\
\hline & p.c./ha & i.a. (g/ha) & \\
\hline Glyphosate $^{2}$ & 2,0 । & 960 & $1 \mathrm{DAS}^{8}$ \\
\hline Glyphosate $^{2}$ & 4,01 & 1920 & $1 \mathrm{DAS}$ \\
\hline Chlorimuron-ethyl $^{3}+$ glyphosate ${ }^{4}$ & $40 \mathrm{~g}+2,0$ & $10+960$ & $1 \mathrm{DAS}$ \\
\hline Chlorimuron-ethyl ${ }^{3}+$ glyphosate ${ }^{4}$ & $80 \mathrm{~g}+2,0$ & $20+960$ & $1 \mathrm{DAS}$ \\
\hline Chlorimuron-ethyl $^{3}+$ glyphosate $^{4}+$ flumioxazin $^{5}$ & $80 \mathrm{~g}+2,01+80 \mathrm{~g}$ & $20+960+40$ & $1 \mathrm{DAS}$ \\
\hline Glyphosate ${ }^{2}+2,4-\mathrm{D}^{6}$ & $2,0|+1,0|$ & $960+868$ & $8 \mathrm{DAS}$ \\
\hline Testemunha no mato & -- & --- & --- \\
\hline
\end{tabular}

${ }^{1}$ Nomes comuns e comerciais: ${ }^{2}$ glyphosate $=$ Roundup, ${ }^{3}$ chlorimuron-ethyl $=$ Classic, ${ }^{4}$ glyphosate $=$ Gliphogan 480 CE, ${ }^{5}$ flumioxazin $=$ Flumyzin 500, '2,4-D = U-46 D-Fluid.

${ }^{7}$ Foi utilizado óleo mineral Assist $(0,5 \%$ v.v.) em todos os tratamentos químicos.

${ }^{8} \mathrm{DAS}=$ dias antes da semeadura

Tabela 2. Condições climáticas no momento das aplicações dos herbicidas. Rondonópolis, MT, 1999-2000.

\begin{tabular}{lcccccc}
\hline Tratamento & Data & Temp. & UR ar & Um. solo & Horário & Ventos \\
\hline Trat. 6 (c/ 2,4-D) & $23 / 11 / 99$ & $28^{\circ} \mathrm{C}$ & $68 \%$ & pouca & $19: 15-19: 30$ & $<3 \mathrm{~km} / \mathrm{h}$ \\
Trat. 1, 2, 3, 4 e 5 & $01 / 12 / 99$ & $26^{\circ} \mathrm{C}$ & $76 \%$ & pouca & $07: 15-08: 45$ & $<3 \mathrm{~km} / \mathrm{h}$ \\
\hline
\end{tabular}

daninhas nos tratamentos, através da contagem do número de plantas $/ \mathrm{m}^{2}$ ( 4 sub-amostras aleatórias de $0,5 \mathrm{~m}^{2}$ por parcela) aos 45 DAA. Com relação à seletividade, os dados não estão apresentados no trabalho pois não foi observado nenhum tipo de fitotoxicidade às plantas da cultura. A avaliação de colheita não foi realizada; entretanto, não houve nenhum sintoma de fitotoxicidade que pudesse afetar a produtividade da cultura.

Para análise estatística dos dados de reinfestação de Commelina benghalensis e Bidens pilosa, utilizou-se o teste de Tukey a $5 \%$ de probabilidade. Os dados analisados foram transformados em $\sqrt{x+1}$ e, posteriormente, foram apresentados os originais nas tabelas. Para Cenchrus echinatus, não houve reinfestação. O tratamento "testemunha no mato" foi retirado da análise por não possuir dados de reinfestação, já que as plantas presentes na área era da infestação original.

\section{RESULTADOS E DISCUSSÃO}

A infestação das plantas daninhas, na área experimental, antes da aplicação dos herbicidas, era composta de Commelina benghalensis, Bidens pilosa e Cenchrus echinatus (Tabela 3 ).
Os dados de percentagem de dessecação das plantas daninhas do experimento, aos 30 dias após a aplicação (DAA) dos herbicidas, considerados os mais importantes para o trabalho, estão contidas na Tabela 4 .

O herbicida glyphosate (960 e $1920 \mathrm{~g} / \mathrm{ha}$ ) foi altamente eficiente no controle de Cenchrus echinatus e Bidens pilosa, proporcionando total dessecação das plantas, aos 21 DAA. Para Commelina benghalensis o controle foi inferior a $80 \%$. Esses dados estão de acordo com Lorenzi et al. (2000).

O tratamento chlorimuron-ethyl+glyphosate $(10+960$ e $20+960 \mathrm{~g} / \mathrm{ha}$ ) foi eficiente no controle de C. benghalensis, proporcionando níveis médios de dessecação acima de $83 \%$, aos 30 DAA. Para C. echinatus e B. pilosa, o tratamento foi altamente eficiente, proporcionando total dessecação das plantas aos 21 DAA.

O tratamento chlorimuron-ethyl+glyphosate+ flumioxazin $(20+960+40 \mathrm{~g} / \mathrm{ha})$ foi eficiente no controle de $C$. benghalensis proporcionando um nível médio de dessecação de $92 \%$, aos 30 DAA. Para C. echinatus e B. pilosa, o tratamento foi altamente eficiente, proporcionando total dessecação das plantas aos 21 DAA.

O tratamento glyphosate $+2,4-\mathrm{D}(960+868 \mathrm{~g} / \mathrm{ha})$ foi altamente eficiente no controle de $C$. benghalensis, $C$. echinatus e $B$. pilosa, proporcionando praticamente total dessecação das plantas aos 21 DAA. 
Tabela 3. Infestação média das plantas daninhas nas testemunhas sem capinas. Rondonópolis, MT, 1999-2000.

\begin{tabular}{lcc}
\hline Espécie Daninha & Infestação & Fase de desenvolvimento \\
\hline Commelina benghalensis (trapoeraba) & $70 \%$ de cobertura & Plantas adultas \\
Cenchrus echinatus (capim-carrapicho) & 63 plaritas $/ \mathrm{m}^{2}$ & Formação de grãos \\
Bidens pilosa (picão-preto) & 36 plantas $/ \mathrm{m}^{2}$ & Plantas adultas \\
\hline
\end{tabular}

Obs.: No caso da trapoeraba, a arquitetura das plantas adultas rizomatadas impossibilitou a contagem do número de plantas

Tabela 4. Percentagem média de dessecação das plantas daninhas aos 30 dias após a aplicação dos herbicidas. Rondonópolis, MT, 1999-2000.

\begin{tabular}{lcccc}
\hline \multicolumn{1}{c}{ Tratamentos } & Dose & \multicolumn{2}{c}{ Dessecação (\%) } \\
\cline { 3 - 5 } & $(\mathrm{g} / \mathrm{ha})$ & $\begin{array}{c}\text { Commelina } \\
\text { benghalensis }\end{array}$ & $\begin{array}{c}\text { Cenchrusec } \\
\text { hinatus }\end{array}$ & $\begin{array}{c}\text { Bidens } \\
\text { pilosa }\end{array}$ \\
\hline Glyphosate & 960 & 71 & 100 & 100 \\
Glyphosate & 1920 & 79 & 100 & 100 \\
Chlorimuron-ethyl + glyphosate & $10+960$ & 85 & 100 & 100 \\
Chlorimuron-ethyl + glyphosate & $20+960$ & 83 & 100 & 100 \\
Chlorimuron-ethyl +glyphosate +flumioxazin & $20+960+40$ & 92 & 100 & 100 \\
Glyphosate + 2,4-D & $960+868$ & 99 & 100 & 100 \\
Testemunha no mato & - & 0 & 0 & 0 \\
\hline
\end{tabular}

Os dados de reinfestação das plantas daninhas indicam o efeito residual dos herbicidas. Para Bidens pilosa observa-se que a reinfestação nos tratamentos com apenas glyphosate (960 e $1920 \mathrm{~g} / \mathrm{ha}$ ) foi bastante alta, maior que 102,5 plantas $/ \mathrm{m}^{2}$, aos $45 \mathrm{DAA}$. A reinfestação nos tratamentos com o herbicida chlorimuron-ethyl foi menor que $1,0 \mathrm{planta} / \mathrm{m}^{2}$, aos 45 DAA. Esses dados demonstram a ocorrência de um efeito residual do herbicida, proporcionando o controle das plantas daninhas ao longo do tempo (Tabela 5).

Este tipo de controle residual, conseguido na operação de manejo, é importante, pois além de reduzir a competição das plantas daninhas no período crítico da cultura, facilita o controle pós-emergente, que pode ser realizado com doses mínimas de herbicidas recomendados. Resultados semelhantes, obtidos com o herbicida chlorimuron-ethyl, foram recentemente relatados por Valente \& Ornelas (2000) para a espécie Bidens pilosa e por Bizzi \& Bianchi (2000) para as espécies $B$. pilosa, Xanthium strumarium e Sida rhombifolia.

A estratégia de se utilizar herbicidas no manejo que, além de aumentar o espectro de controle do glyphosate, proporcionam efeito residual para o controle das plantas daninhas, já é amplamente utilizada á algum tempo com o herbicida 2,4-D. Observa-se, entretanto, que a reinfestação de $B$. pilosa no tratamento glyphosate $+2,4-\mathrm{D}(960+868 \mathrm{~g} / \mathrm{ha})$ foi relativamente alta, com 41 planta/ $\mathrm{m}^{2}$ aos 45 DAA. A utilização do herbicida 2,4-D no manejo para o plantio direto da soja possui algumas restrições como a necessidade de se esperar, no míni- mo, 10 dias entre a aplicação e a semeadura (Rodrigues e Almeida, 1998) e a possibilidade de ocorrência de danos à cultura quando há pouca umidade no solo.

Para a espécie Commelina benghalensis observa-se uma semelhança entre os resultados dos diferentes tratamentos (não houve diferença significativa), demonstrando que o efeito residual dos herbicidas não foi suficiente para impedir a reinfestação da planta daninha.

\section{CONCLUSÕES}

Os herbicidas e doses estudados, aplicados antes da semeadura da cultura, no manejo de plantas daninhas para o plantio direto, não causam toxicidade às plantas de soja, variedade Emgopa 313.

Os tratamentos chlorimuron-ethyl+glyphosate $(10+960$ e $20+960 \mathrm{~g} / \mathrm{ha}$ ), chlorimuron-ethyl+glyphosate+flumioxazin $(20+960+40 \mathrm{~g} / \mathrm{ha})$ e glyphosate+2,4-D (960+868 g/ha), são eficientes na dessecação de Commelina benghalensis, Cenchrus echinatus e Bidens pilosa. Glyphosate isolado (960 e $1920 \mathrm{~g} /$ ha) é eficiente na dessecação de C. echinatus e B. pilosa.

O herbicida chlorimuron-ethyl ( 10 e $20 \mathrm{~g} /$ ha) aplicado juntamente com o glyphosate, no manejo, proporciona ao tratamento um efeito residual significativo para Bidens pilosa, reduzindo a infestação da planta daninha durante o ciclo da cultura da soja. 
Tabela 5. Número médio de plantas de Bidens pilosa e Commelina benghalensis germinadas aos 45 DAA. Rondonópolis, MT, 1999-2000.

\begin{tabular}{|c|c|c|c|}
\hline \multirow{2}{*}{ Tratamentos } & \multirow{2}{*}{$\begin{array}{c}\text { Dose } \\
(\mathrm{g} / \mathrm{ha})\end{array}$} & \multicolumn{2}{|c|}{ № plantas $/ \mathrm{m}^{2}$} \\
\hline & & B. pilosa & C. benghalensis \\
\hline Glyphosate & 960 & $137,8 a^{1}$ & 13,8 a \\
\hline Glyphosate & 1920 & 102,5 a & 10,0 a \\
\hline Chlorimuron-ethyl+glyphosate & $10+960$ & $1,0 \mathrm{~b}$ & 19,0 a \\
\hline Chlorimuron-ethyl+glyphosate & $20+960$ & $0,2 \mathrm{~b}$ & 15,0 a \\
\hline Chlorimuron-ethyl+glyphosate+flumioxazin & $20+960+40$ & $0,2 \quad b$ & 12,5 a \\
\hline Glyphosate+2,4-D & $960+868$ & 41,0 ab & 23,2 a \\
\hline Média Geral & --- & 47,12 & 15,58 \\
\hline Teste $\mathrm{f}$ (tratamentos) & & 8,15 & $0,63^{\mathrm{ns}}$ \\
\hline Coeficiente de Variação (\%) & & 62,52 & 37,11 \\
\hline
\end{tabular}

${ }^{1}$ Médias seguidas de letras iguais, nas colunas, não diferem entre si pelo teste de Tukey a $5 \%$ de probabilidade.

\section{LITERATURA CITADA}

\section{ASSOCIAÇÃO NACIONAL DE DEFENSIVOS AGRÍCOLAS} - ANDEF. Defesa vegetal. São Paulo, SP: ANDEF, 1987. $19 \mathrm{p}$.

BIZZI, A. F.; BIANCHI, MA. Eficácia da mistura de chlorimuron-ethyl com glyphosate na dessecação e residual sobre plantas daninhas na soja. In: CONGRESSO BRASILEIRO DA CIÊNCIA DAS PLANTAS DANINHAS, 22., 2000, Foz do Iguaçu, PR. Resumos... Londrina, PR: SBCPD, 2000.p.118.

BLANCO, H.G. et al. Observações sobre o período em que as plantas daninhas competem com a soja [Glycine max (L.) Merrill]. O Biológico, v.39, n.2, p. 31-35, 1973.

BLANCO, H.G., OLIVEIRA, D.A., ARAÚJO, J.B.M. Período crítico de competição de uma comunidade natural de mato em soja [Glycine max (L.) Merrill]. In: SEMINÁRIO NACIONAL DE PESQUISA DE SOJA, 1., 1978, Londrina. Anais... Londrina: EMBRAPA-CNPSO, 1978. p.151-157.

CARVALHO, F.T. Integração de práticas culturais e dosagens de herbicida aplicado em pós-emergência, no controle de plantas daninhas e produtividade da cultura da soja [Glycine max (L.) Merrill]. Jaboticabal: UNESP-FCAV, 1993. 94 p. Dissertação (Mestrado em Agronomia). Faculdade de Ciências Agrárias e Veterinárias, Universidade Estadual Paulista, 1993.

LORENZI, H. et al. Manual de identificação e controle de plantas danin has: plantio ditreto e convencional. 5 ed., Nova Odessa, SP: Plantarum, 2000. 339 p.

RODRIGUES, B.N.; ALMEIDA, F.S. Guia de herbicidas. 4 ed., Londrina: Edição dos Autores, 1998. 648 p.

SPADOTTO, C. A.; MARCONDES, D. A. S.; LUIZ, A. J. B.; SILVA, C. A. R. Determinação do período crítico para prevenção da interferência de plantas daninhas na cultura da soja: uso do modelo "broken-stick". Planta Daninha, Brasília, v. 12, n. 2, p. 59 - 62, 1994.

VALENTE, T.O.; ORNELAS, A. Efeito residual de chlorimuronethyl aplicado em mistura com glyphosate na dessecação em condições de cerrado. In: CONGRESSO BRASILEIRODA CIÊNCIA DAS PLANTAS DANINHAS, 22., 2000, Foz do Iguaçu, PR. Resumos... Londrina, PR: SBCPD, 2000.p.117. 
Fernando T. de Carvalho

Anexo 1. Dados de precipitação (mm). Rondonópolis-MT, 1999-2000.

\begin{tabular}{|c|c|c|c|}
\hline DIA & DEZEMBRO & JANEIRO & FEVEREIRO \\
\hline 1 & 0 & 10 & 25 \\
\hline 2 & 35 & 40 & 3 \\
\hline 3 & 0 & 0 & 7 \\
\hline 4 & 15 & 0 & 0 \\
\hline 5 & 15 & 0 & 0 \\
\hline 6 & 38 & 5 & 0 \\
\hline 7 & 22 & 0 & 59 \\
\hline 8 & 0 & 0 & 2 \\
\hline 9 & 10 & 0 & 0 \\
\hline 10 & 29 & 0 & 13 \\
\hline 11 & 70 & 0 & 9 \\
\hline 12 & 11 & 0 & 55 \\
\hline 13 & 0 & 0 & 0 \\
\hline 14 & 0 & 0 & 106 \\
\hline 15 & 0 & 0 & 37 \\
\hline 16 & 0 & 0 & 29 \\
\hline 17 & 0 & 13 & 0 \\
\hline 18 & 0 & 12 & 16 \\
\hline 19 & 10 & 3 & 3 \\
\hline 20 & 0 & 0 & 0 \\
\hline 21 & 0 & 0 & 28 \\
\hline 22 & 0 & 0 & 3 \\
\hline 23 & 0 & 0 & 2 \\
\hline 24 & 14 & 12 & 0 \\
\hline 25 & 19 & 23 & 0 \\
\hline 26 & 5 & 2 & 0 \\
\hline 27 & 0 & 22 & 0 \\
\hline 28 & 0 & 17 & 0 \\
\hline 29 & 0 & 35 & 0 \\
\hline 30 & 0 & 12 & - \\
\hline 31 & 3 & 0 & - \\
\hline
\end{tabular}

